\section{Influence of Implant Surfaces on Os seointegration: A Histomorphometric and Implant Stability Study in Rabbits}

Priscilla Barbosa Ferreira Soares ${ }^{1}$, Camilla Christian Gomes Moura ${ }^{2}$, Marcela Claudino $^{3}$, Valessa Florindo Carvalho ${ }^{4}$, Flaviana Soares Rocha', Darceny Zanetta-Barbosa ${ }^{1}$

\author{
'Department of Oral and Maxillofacial \\ Surgery and Implantology, \\ UFU - Universidade Federal de \\ Uberlândia, Uberlândia, MG, Brazil \\ ${ }^{2}$ Department of Endodontics, \\ UFU - Universidade Federal de \\ Uberlândia, Uberlândia, MG, Brazil \\ ${ }^{3}$ Department of Dentistry, UEPG \\ - Universidade Estadual de Ponta \\ Grossa, Ponta Grossa, PR, Brazil \\ ${ }^{4}$ Department of Operative \\ Dentistry and Dental Materials, \\ UFU - Universidade Federal de \\ Uberlândia, Uberlândia, MG, Brazil
}

Correspondence: Correspondence: Prof. Dr. Darceny Zanetta-Barbosa, Avenida Pará S/N, Campus Umuarama, Bloco 4T, Bairro Umuarama, 38400- 902 Uberlândia, MG, Brasil. Tel./ Fax: +55-34-3225-8148. email: darceny_@hotmail.com

Key Words: dental implant, resonance frequency, histomorphometry, wettability, rabbits

\section{Introduction}

In the past twenty years, optimization on titanium implant surfaces has been advocated for improving the osseointegration process. This aspect impacting mainly in specific clinical situations with alveolar bone has reduced mineral density or is required rapid healing for early loading rehabilitation $(1,2)$. Several methods have been developed to obtain different implant surfaces such as plasma spray, grid blasting, acid etching and anodization $(1,3,4)$, which may result on variations of the topography and chemical composition $(1,3,5)$. The implant surface determined by these treatments may affect the protein adsorption, platelet activation and aggregation, fibrin retention (6), cell surface interaction, and cell tissue development at implant/bone interface $(1,3,5,7)$.

The surface topography of the implant is another characteristic that may interfere on the bone biological response (4,8-10). Moderately microroughness surface have proven to be superior to smooth counterparts $(8,9)$, improving parameters as bone-implant contact, new bone formation and removal torque $(11,12)$. Surface chemistry is also an important characteristic for implant performance since its affects on surface energy and wettability $(5,7)$. The implant surface energy measured indirectly by the liquid-solid contact angle (CA) affects the initial bloodimplant interactions, the initial stages of cell adhesion, proliferation and differentiation $(5,13)$. Generally, CA ranges from 0 to $180^{\circ}$, values above $90^{\circ}$ characterizes the hydrophobic surface, while values lower than $90^{\circ}$ are designated hydrophilic surfaces, and values very close to $0^{\circ}$ are considered superhydrophilic surfaces (5).

Wetting is reduced on microroughned surfaces created by acid etched, sandblasting or anodization $(4,5)$. Nowadays, most implant surfaces clinically evaluated are of hydrophilic type $(5,14,15)$. SLActive ${ }^{\circledR}$ (Institut Straumann $\mathrm{Ag}$, Basel, Switzerland) was introduced on the market as a superhydrophilic titanium implant surface, which is produced by sandblasting followed by etching using a mixture of $\mathrm{HCl}$ and $\mathrm{H}_{2} \mathrm{SO}_{4}$ followed by storing in $\mathrm{NaCL}$ solution (12). SLActive has been evaluated in vitro $(6,12)$ and in vivo $(7,11,12,16)$. Recently, a new superhydrophilic implant was commercially available, Acqua ${ }^{\circledR}$ (Neodent, Curitiba, $\mathrm{PR}, \mathrm{Brazil})$, which is produced by a similar method than SLActive ${ }^{\circledR}$, resulting in similar microroughness and 
contact angle (17).

In this way, the aim of this study was to investigate the new commercially available dental implant on osseointegration by a histomorphometric evaluation of bone-implant-contact (BIC), bone area fraction occupied (BAFO) and resonance frequency analysis (RFA) after 2 and 4 weeks in rabbit tibiae. The null hypothesis was that the implant surface modification employed on Acqua implants has no effect of histomorphometric parameters.

\section{Material and Methods}

Thirty-two morse taper implant junctions (Titamax CM; Neodent, Curitiba, PR, Brazil), measuring $3.5 \mathrm{~mm}$ in diameter and $7 \mathrm{~mm}$ in length, were divided into the following 2 groups $(n=8)$ according to surface treatment: sandblasting with abrasive particles followed by acid etching (Neo; Neoporos) and Neo maintained in an $0.9 \%$ sodium chloride isotonic solution (Aq; Acqua). After installation of the implant, the groups Neo and Aq were divided according to the experimental periods of 2 and 4 weeks.

\section{Surgical Procedure}

Sixteen New Zealand white rabbits weighing between 3.0 and $3.5 \mathrm{~kg}$ were included in this study. The experimental protocol was evaluated and approved by the Ethics Committee for Animal Research (Protocol \#093/12, Universidade Federal de Uberlândia, Brazil). The guidelines of the Brazilian College of Animal Experimentation were followed in all animal protocols.

Prior to surgery, the legs of animals were shaved and the tibiae area was cleaned with a $0.2 \%$ chlorhexidine solution (Rioquimica, São José do Rio Preto, SP, Brazil). The animals were anaesthetized with an intramuscular injection of a combination of $0.25 \mathrm{mg}$ of ketamine $/ \mathrm{kg}$ of body weight (Ketamina Agener; Agener União Ltda., São Paulo, SP, Brazil) and $0.5 \mathrm{mg}$ of xylazine $/ \mathrm{kg}$ of body weight (Rompum ${ }^{\circledR}$ Bayer S.A. São Paulo, SP, Brazil). The infiltration of anesthesia was applied using $2 \%$ lidocaine and 1:100,000 epinephrine (Alphacaine $0.5-1 \mathrm{~mL} / \mathrm{site}_{\text {, }}$ $\mathrm{DFL}$, Rio de Janeiro, RJ, Brazil) to reduce stimulation during surgery, generating vasoconstriction.

A 3-cm-long incision to access the periosteum was performed and a flap was reflected for exposure of the rabbits' tibias. Implants were placed using a progressive sequence of drills, under constant irrigation with saline, according to the manufacturer's instructions. All drilling procedures were conducted at $1200 \mathrm{rpm}$. One implant was installed on the proximal site of each tibia $(n=8)$. The soft tissues were sutured in separate layers using an interrupted suture (\#5.0 nylon sutures Ethicon ${ }^{\circledR}$; Johnson \& Johnson Medical Ltd., Blue Ash, Ohio, United States). To prevent infection, daily intramuscular injections of Cefazolin (Yuhan
Company; $250 \mathrm{mg}$ ) were given for 1 week. To prevent pain, a dose of an anti-inflammatory Meloxicam ${ }^{\circledR} 0.3 \mathrm{mg} / \mathrm{kg}$ (Ourofino, São Paulo, SP, Brazil) were administrated. Each rabbit was maintained in individual cages and received food and water.

\section{Resonance Frequency Analysis}

Values of implant stability quotient (ISO) were obtained immediately after implant placement (primary stability) and after 2 or 4 weeks (secondary stability), according to experimental group. For every series of RFA measurements, the ISQ values were recorded using a specific device (Osstell; Integration Diagnostics, Göteborg, Sweden) in two different directions: buccal and palatal. A transducer (Smartpegs) was attached to the implant, and ISO ranging from 1 to 100 was recorded. The Osstells was brought into very close contact with the Smartpegs, although without touching it, until an audible signal confirmed that the measurement had been taken.

\section{Histological Procedures}

The animals were randomly sacrificed after 2 and 4 weeks by an intramuscular injection of high dose of the anesthetic solution and the tibiae containing the implants were removed. Tissue blocks containing the implant were fixed in 10\% buffered formalin solution for $24 \mathrm{~h}$ and washed in running water for $24 \mathrm{~h}$. These bone/implant blocks were dehydrated in an increasing ethanol series (70\%, 80\%, 90\% and 100\%) with 7 days for each phase at $5{ }^{\circ} \mathrm{C}$. Following dehydration, the samples were embedded in a methacrylate-based resin (LR White hard grade, London Resin Company, Theale, Berkshire, UK) according to the manufacturer's instructions. After polymerization, the specimens were sectioned along the longitudinal axis with a precision diamond disk (Struers, Ballerup, Hovedstaden, Denmark), resulting in two sections with approximately 300 $\mu \mathrm{m}$ thickness. The sections were fixed on the acrylic plates using cyanoacrylate adhesive (Super bonder Loctite, São Paulo, SP, Brazil). The slices were finished using abrasive papers sequence $(\# 120,220,320,500,1200$ and $2000 \mu \mathrm{m})$ (Struers, Ballerup) in a polishing machine (TegraSystem, Struers, Ballerup) under water irrigation. The sections, reduced to a final thickness of $30 \mu \mathrm{m}$, were stained with toluidine blue and observed under optical microscope.

\section{Histomorphometric Analysis}

All histological sections were identified with a random numerical sequence in order to codify experimental periods and groups, by independent evaluator. Histomorphometric evaluation was performed using an optical microscope (Axion Imager A1M, Carl Zeiss, Germany) attached to a digital camera (Axiocam ICc3, Carl Zeiss, Germany). The 
acquired digital images were analyzed by a single and calibrated blind examiner for both experimental groups and both periods. Osseointegration process was evaluated using the bone-to-implant contact (BIC) and bone area fraction occupancy (BAFO) parameters quantified using software Image Tool 3.0 (San Antonio Dental School, University of Texas Health Science, TX, USA). The regions of bone-to-implant contact (BIC) along the implant perimeter were subtracted from the total implant perimeter and the calculations were performed to determine the BIC. For bone area fraction occupancy (BAFO), firstly was obtained the total area of threads and the area occupied by space or no-bone, and after was determine the percentage of total area of threads occupied by bone tissue.

\section{Statistical Analysis}

The BIC, BAFO and ISO data were tested for normal distribution (Kolmogorov-Smirnov) and equality of variances (Levene's test), followed by parametric statistical tests. All data were analyzed by two-way ANOVA (Implant surface and period of evaluation) followed by Tukey's test. Pearson's correlations test was used to verify the correlation between BIC and BAFO values. All statistical analyses were carried out with the statistical package Sigma Plot version 13.1 (Systat Software, Inc., San Jose, CA, USA) using a significance level of $\alpha=0.05$.

\section{Results}

\section{Histomorphometric Values}

Two-way ANOVA showed no significant effect of type of implant ( $p=0.699)$, period of evaluation $(p=0.10)$ or the interaction between type of implant and period of evaluation ( $p=0.542)$. For Acqua implant the mean BIC after 2 weeks was $56.6 \pm 16.6 \%$ and after 4 weeks was
$71.2 \pm 11.7 \%$. For Neoporos implant the mean BIC after 2 weeks was $60.0 \pm 16.5 \%$ and after 4 weeks was $63.7 \pm 15.7 \%$.

Two-way ANOVA showed no significant effect of type of implant $(p=0.683)$, period of evaluation $(p=0.653)$ and the interaction between type of implant and period of evaluation ( $p=0.436$ ). For Acqua implant the mean BAFO after 2 weeks was $67.7 \pm 10.2 \%$ and after 4 weeks was $75.1 \pm 11.7 \%$. For Neoporos implant the mean BAFO after 2 weeks was $69.7 \pm 19.5 \%$ and after 4 weeks was $68.6 \pm 8.1 \%$.

\section{RFA Values}

Means and standard deviation values of implant stability quotient for animals sacrificed after 2 weeks are shown on Figure 1A. Two-way ANOVA showed significant effect for period of evaluation $(p<0.001)$, however no significance was found for type of implant ( $p=0.827)$, or for the interaction between type of implant and period of evaluation ( $p=0.713)$. For Acqua implant the mean IQF values measured immediately was $51.9 \pm 10.8 \mathrm{~N} / \mathrm{cm}$ and after 2 weeks was $73.6 \pm 13.5 \mathrm{~N} / \mathrm{cm}$. For Neoporos implant the mean IQF values measured immediately was $52.7 \pm 13.2$ $\mathrm{N} / \mathrm{cm}$ and after 2 weeks was $70.5 \pm 13.0 \mathrm{~N} / \mathrm{cm}$.

Means and standard deviation values of implant stability quotient for animals sacrificed after 4 weeks are shown on Figure 1B. Two-way ANOVA showed significant effect for period of evaluation $(p=0.001)$, however no significance was found for type of implant ( $p=0.118)$, or the interaction between type of implant and period of evaluation $(p=0.745)$. For Acqua implant the mean IQF values measured immediately was $51.9 \pm 7.1 \mathrm{~N} / \mathrm{cm}$ and after 4 weeks was $65.0 \pm 5.7 \mathrm{~N} / \mathrm{cm}$. For Neoporos implant the mean IQF values measured immediately was $57.3 \pm 10.3$ $\mathrm{N} / \mathrm{cm}$ and after 4 weeks was $68.3 \pm 3.0 \mathrm{~N} / \mathrm{cm}$.

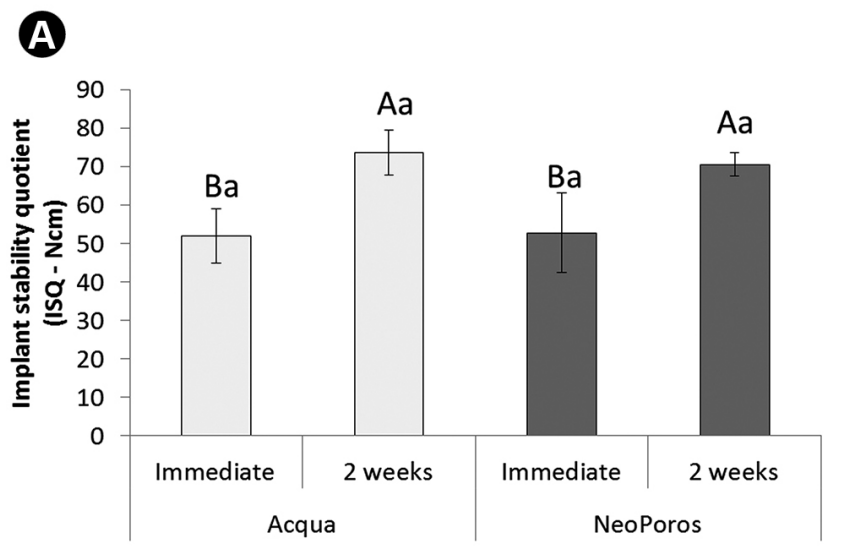

\section{B}

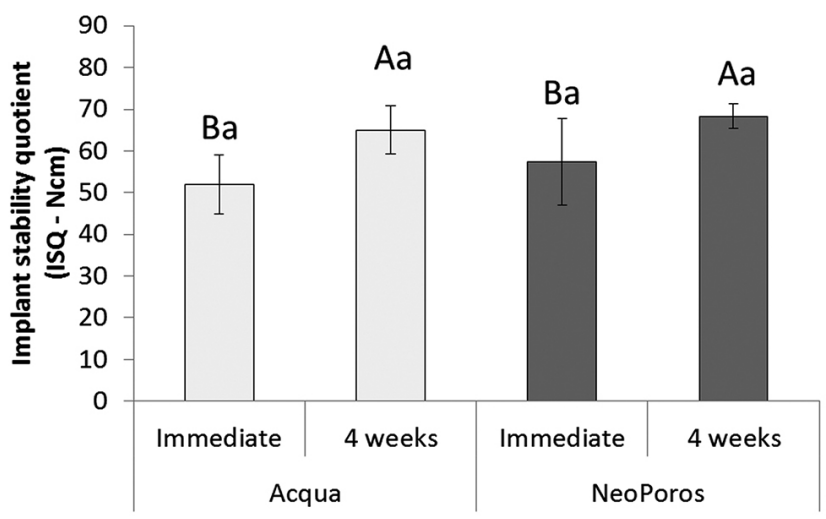

Figure 1. A: Implant stability quotient values for 2 weeks. Different letters represent significant difference, uppercase letter for periods of evaluation and lower case letters for implant type comparison; B: Implant stability quotient values for 4 weeks. Different letters represent significant difference, uppercase letter for periods of evaluation and lower case letters for implant type comparison. 


\section{Correlations}

The Pearson correlations between different parameters are shown on Figure $2 \mathrm{~A}-\mathrm{C}$. There was statistically significant correlation between BIC values and BAFO values (Pearson correlation coefficient: $0.541, p=0.009$ ). Individual BIC values and BAFO values had no significant correlations with ISO values (BIC: Pearson correlation coefficient: 0.0914, $p=0.686$; BAFO: Pearson correlation coefficient: 0.329, $P=0.135$ ).
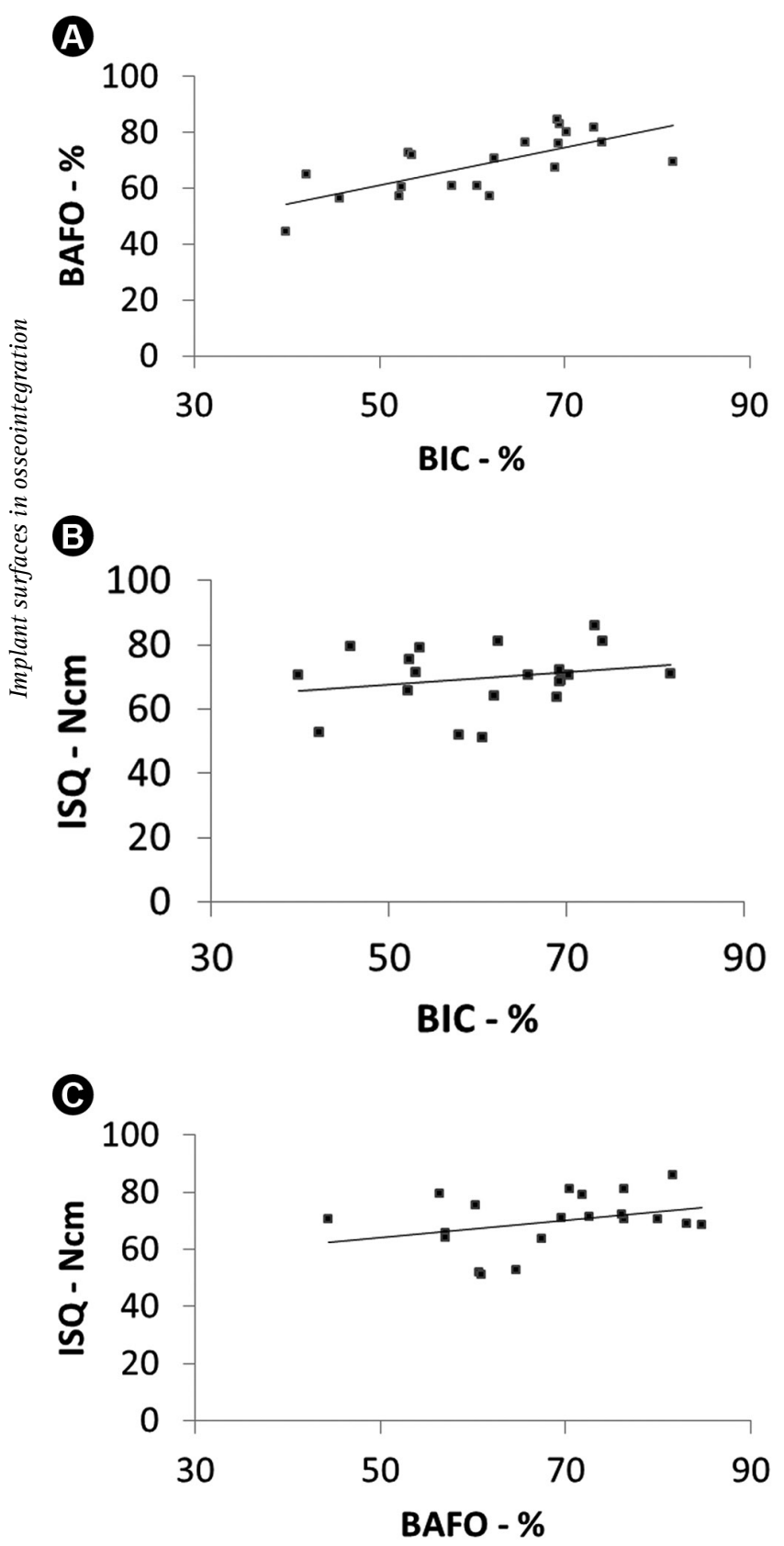

Figure 2. A: Correlation of BIC and BAFO values; B: correlation of BIC and ISQ values; C: correlation of BAFO and ISQ values.

\section{Histological Observations}

Qualitative microscopic evaluation demonstrated new bone formation, visible as blue stain, adjacent to the implant surface in all of the samples. The threads were tightly lodged in surrounding cortical bone. After 2 weeks (Figs. $3 \mathrm{~A}$ and $4 \mathrm{~A})$, new bone matrix was interposed between the implants and bone walls indicating contact osteogenesis. There were no signs of massive resorption. After 4 weeks (Figs. 3B and 4B), both implants surfaces were surrounded by newly formed bone with trabeculae of immature bone, increasing in thickness of the cortical bone in contact with the implant and more resorption e substitution.

\section{Discussion}

It was the aim of this animal study in rabbits to compare the osseointegration performance of two microrough commercially implants at 2 and 4 weeks after installation of dental implants with an identical shape and geometry. The implants were evaluated histologically by means BIC and BAFO and RFA. The null hypothesis was accepted once the implant surface modification employed on Acqua implants has no effect of histomorphometric parameters.

$\mathrm{BIC}$ and BAFO are long established measures for osseointegration in scientific literature $(7,8,10,11,16-20)$. BAFO reflects the bone occupancy rate, which can be filled by newly formed bone via distance osteogenesis or contact osteogenesis, such as for bone fragments compressed between bone wall. BIC shows new bone formation in contact with implant surface, which has been related to contact osteogenesis. However, the proportion of BIC depends on a number of factors including surgical technique, site of implantation, time and implant design. The present study was delineated to minimize the effect of these variables, as the effect of surface energy/wettability was the focus.

Several in vitro studies have demonstrated that hydrophilic surfaces tend to enhance osteoblast adhesion, proliferation, differentiation and bone mineralization compared to hydrophobic surfaces $(5,13)$. In vivo studies have also been demonstrated that higher hydrophilicity surface correlates positively with faster osteogenesis $(7,16)$. However, despite the greater hydrophilicity presented by surface Aq compared to Np surface (17), the BIC values were not significantly different between the two groups, and did not vary as a function of period of evaluation. These findings differ from other studies in which hydrophobic surfaces and highly hydrophilic surfaces were compared $(12,16)$. Those studies compared implants with surface SLA and SLActive, which resemble the surfaces tested regarding the roughness and wettability. Similarly to implants SLActive, the surface Aq was obtained by sandblasted and acid-etched treatment followed by storage in ampules containing 
isotonic $\mathrm{NaCl}$ solution (17). The submersion of the implant in isotonic solution appears to protect the Ti surface from atmospheric contamination, thus preserving a chemically reactive surface (21). X-ray photoelectron microscopic analysis showed a lower carbon concentration and high oxygen values on both SLActive $(7,10,12)$ and Aq surfaces (17), promoting a super-hydrophilic surface. Data from previous researches confirm that contact angle of SLActive
(12) and $\mathrm{Aq}(17)$ are similar, with values $<5^{\circ}$. Despite of the similarities between $\mathrm{Aq}$ and SLActive surfaces, differences in BAFO and BIC parameters compared to the studies using SLActive may be related to experimental design.

The implant design, the healing chamber dimensions and type of bone (cortical or trabecular) exert strong effect on osseointegration over time (20). It is recognized that drilling protocol (oversized, intermediate or undersized)
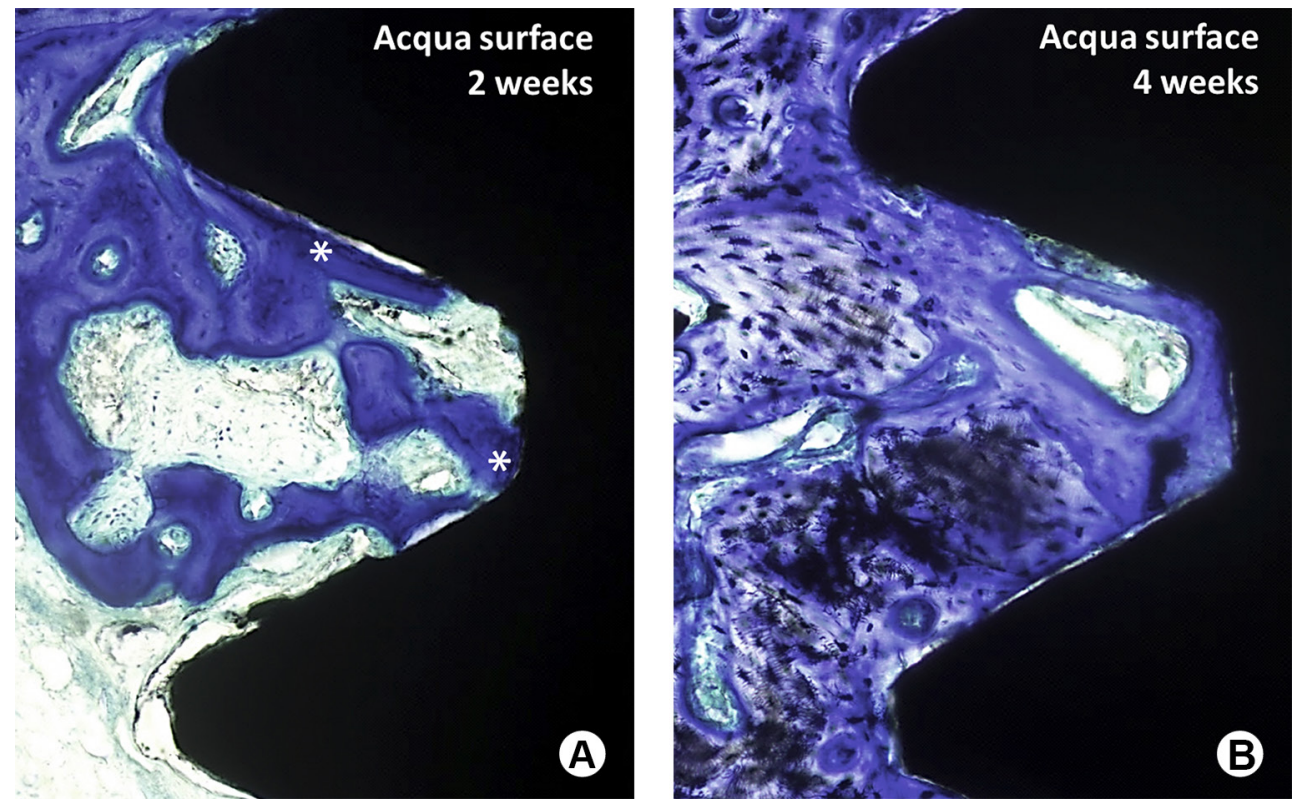

Figure 3. Sections of Acqua Ti implants and the surrounding tissue; A: after 2 weeks; B: after 4 weeks. At 2 weeks, thin layer of newly formed bone $(*)$. At 4 weeks, similar conditions as those of 2 weeks were observed, with active remodeling of old bone structures.
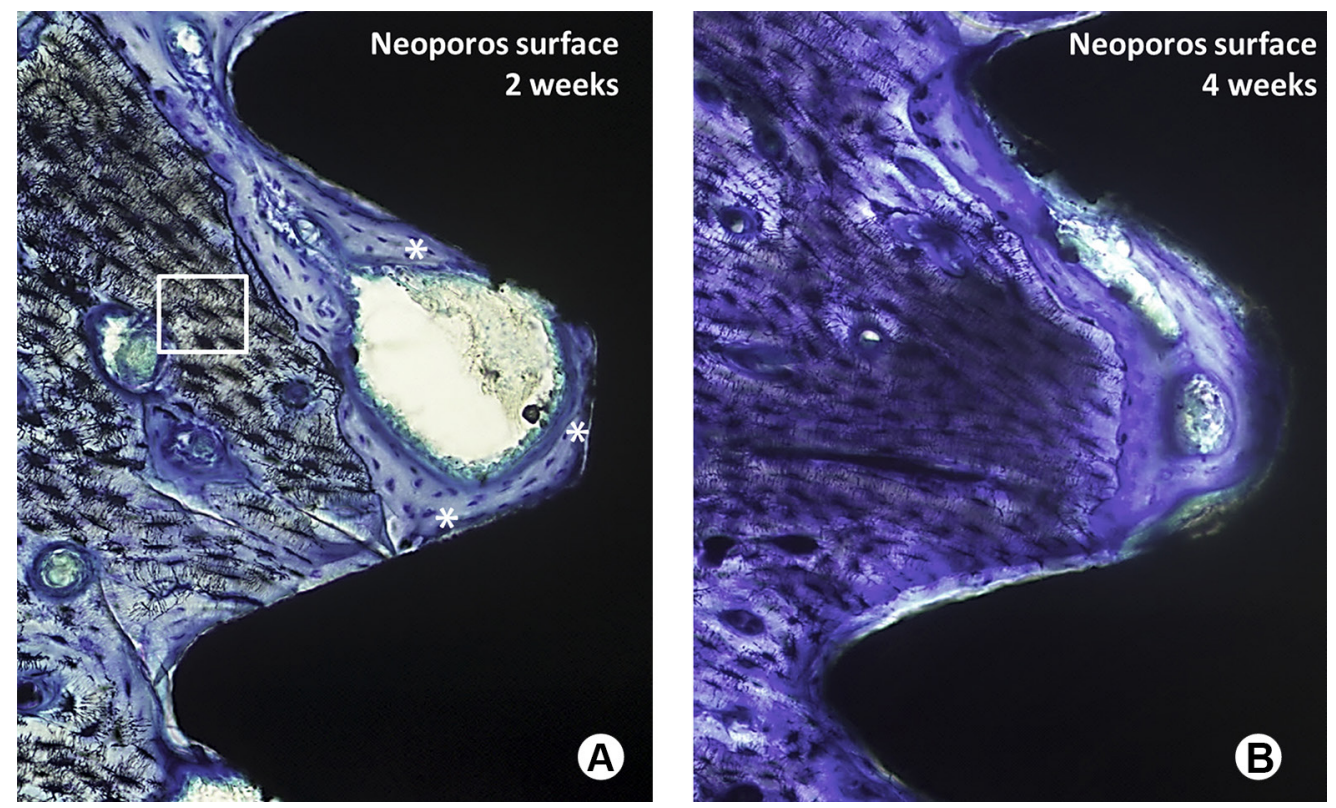

Figure 4. Sections of Neoporos Ti implants and the surrounding tissue; A: after 2 weeks; B: after 4 weeks. At 2 weeks, thin layer of newly formed bone $(*)$, which in some areas was connected to trabecular of lamellar bone (square) in intimate contact with both surface. At 4 weeks, were observed similar conditions as 2 weeks, with active remodeling of old bone structures. 
result in different biological responses with higher $\mathrm{BIC}$ and BAFO values for intermediate drilling (22). This fact seems to be related to the blood's clot ability to fill the space between the bone wall and the implant threads which facilitates intramembranous like bone formation at bone interface (20). The current study did not created healing chamber, generating a press-fit condition in the bony walls with a little space between the implant and bone. It is possible to speculate that implant macrogeometry and insertion technique had reflected in the lack of differences in BIC and BAFO values between for Neo and Aq surfaces. Furthermore, old bone should be resorbed before new bone formation in areas of close contact between bone and implant surface (16). This assumption may explain why the present findings agree partially with Sartoretto et al. (17). Those authors also observed no statistically significant differences in the BIC values and BAFO between the Aq and $\mathrm{Np}$ at 14 days, although they have found in the 28day period. In the same way as presented in this study, the authors had no detected increasing of the percentage of BAFO along the time. It is also important to note that such study did not specify in which region BIC and BAFO analyses were performed; if they were on the cortical or medullar, or on both, since this factor may impair on the outcome. These findings corroborate the positive effects of a highly hydrophilic surface, such as Aq, may have been minimized by the implant insertion conditions.

The present study also evaluated mechanical implant stability by RFA method. ISQ values obtained in RFA analysis allow measuring the primary and secondary stability (19). Primary stability measured immediately after implant installation have been related to a tight-fitting between the implant surface and marginal or apical bone. On the other hand, secondary stability is consequence of new bone formation and remodeling process $(19,23)$, which was evaluated on 14 and 28 days post implant installation. Considering that $\mathrm{Aq}$ and Neo possess the same macrogeometry and were installed on the same region of tibia, was expected a lack of difference between the groups for primary stability. This lack of differences in ISO values between the groups $\mathrm{Aq}$ and $\mathrm{Np}$ was maintained for all experimental periods. Though some studies have shown that secondary stability is correlated to the surface properties of dental implants (19), the present findings did not support this theory. Other factors, such as strong bone anchorage $(18,24)$, stiffness of the surrounding bone $(2,18,19)$, type of implant used and surgical technique $(18,25)$ may support the current results. Nevertheless, the increases in RFA values that occur during implant healing and have been attributed to increased bone anchorage cannot be explained by histomorphometric data $(18,25)$. As observed in this study, no correlations between histomorphometric parameters of osseointegration and ISO values could be identified by other authors $(2,18,24,25)$. Considering that histological sections are two-dimensional images, and do not represent the entire implant-bone contact around the implant, and also that sections does not indicate the mechanical strength, it is not surprising the lack of correlation between these parameters (25). The authors recognized a limitation of this study, since it was not tested either the implant surface on cortical bone under superinstrumentation conditions during implant installation. Under these conditions, the Aq surface tends to induce more bone neoformation, due the superhidrophilic of Aq surface.

In conclusion, implants installed in cortical bone with same roughness but opposed wettability characteristics did not result in differences in new bone formation or implant stability on initial periods, indicating that in this bone site the chemical alterations on implant surface had no effect on short period of implant bone integration. Both implant surfaces, Aq and Neo, were able to produce similar implant bone integration when normal cortical bone instrumentation was performed.

\section{Resumo}

0 objetivo deste estudo foi avaliar a estabilidade e osseointegração de implantes com superfícies com diferentes molhabilidades empregando análise de frequência de ressonância (RFA) e histomorfometria (contato implante ósseo, BIC, e fração de área óssea ocupada, BAFO), nos periodos de 2 e 4 semanas em tibias de coelhos. Trinta e dois implantes cone Morse (comprimento $7 \mathrm{~mm}$, diâmetro $3,5 \mathrm{~mm}$ ), foram divididos de acordo com tratamento de superficie $(n=8)$ : Neo, superficie jateada e condicionada com ácido; e Aq, superfície jateada e condicionada com ácido e mantida em solução isotônica de cloreto de sódio a 0,9\%. Dezesseis coelhos tipo Nova Zelândia foram utilizados neste estudo. Dois implantes de cada grupo foram instalados nas tíbias direita e esquerda de acordo com os periodos experimentais. Os valores de RFA (Ostell ${ }^{\circledR}$ ) foram obtidos imediatamente e após o sacrifício (2 e 4 semanas). 0s blocos ósseos/implante foram processados para análise histomorfométrica. Os dados foram analisados usando ANOVA fatorial seguido pelo teste de Tukey e também por meio de correlação de Pearson para os fatores RFA, BIC e BAFO $(P=0,05)$. Nenhum efeito significativo dos fatores tipo de implante, periodo de avaliação e da interação entre o tipo de implante e período de avaliação foram observados para os valores de BIC e BAFO. Apenas o periodo de avaliação resultou em efeito significativo para valores RFA após 2 semanas $(p=0,001)$, e 4 semanas $(p<0,001)$. Os valores de RFA valores foram significativamente mais elevados no final do período de avaliação em comparação com os obtidos em inicialmente. Houve correlação significativa entre os valores BIC e BAFO $(p=0,009)$. Ambas as superfícies de implantes, Aq e Neo, são capazes de produzir adequada integração osso/implante em condição normal de instrumentação do osso cortical.

\section{Acknowledgements}

This study was supported by the research funding agencies FAPEMIG and CAPES. The authors are grateful to Neodent for full donation of the implants used in this study.

\section{References}

1. Le Guéhennec L, Soueidan A, Layrolle P, Amouriq Y. Surface treatments of titanium dental implants for rapid osseointegration. Dent Mater 
2007:23:844-854.

2. Sennerby L, Meredith N. Implant stability measurements using resonance frequency analysis: biological and biomechanical aspects and clinical implications. Periodontol 2000 2008;47:51-66.

3. Mendonça G, Mendonça DB, Aragão FJ, Cooper LF. Advancing dental implant surface technology- from micron- to nanotopography. Biomaterials 2008;29:3822-3835.

4. Novaes $A B$ Jr, de Souza SL, de Barros RR, Pereira KK, lezzi G, Piattelli A. Influence of implant surfaces on osseointegration. Braz Dent J 2010;21:471-481.

5. Gittens RA, Scheideler L, Rupp F, Hyzy SL, Geis-Gerstorfer J, Schwartz Z,et al. A review on the wettability of dental implant surfaces II: Biological and clinical aspects. Acta Biomater 2014;10:2907-2918.

6. Kopf BS, Schipanski A, Rottmar M, Berner S, Maniura-Weber K. Enhanced differentiation of human osteoblasts on Ti surfaces pretreated with human whole blood. Acta Biomater 2015;19:180-190.

7. Buser D, Broggini N, Wieland M, Schenk RK, Denzer AJ, Cochran DL, et al. Enhanced bone apposition to a chemically modified SLA titanium surface. J Dent Res 2004;83:529-533.

8. Wennerberg A, Albrektsson T. Effects of titanium surface topography on bone integration: a systematic review. Clin Oral Implants Res 2009;20:172-184.

9. Xavier SP, Ikuno KE, Tavares MG. Enhanced bone apposition to Brazilian microrough titanium surfaces. Braz Dent J 2010;21:18-23.

10. Park IP, Kim SK, Lee SJ, Lee JH. The relationship between initial implant stabilit quotient values and bone-to-implant contact ratio in the rabbit tibia. J Adv Prosthodont 2011;3:76-80.

11. Dagher M, Mokbel N, Jabbour G, Naaman N. Resonance frequency analysis, insertion torque, and bone to implant contact of 4 implant surfaces: comparison and correlation study in sheep. Implant Dent 2014;23:672-678.

12. Wennerberg $A$, Jimbo $R$, Stübinger $S$, Obrecht $M$, Dard $M$, Berner S. Nanostructures and hydrophilicity influence osseointegration: a biomechanical study in the rabbit tibia. Clin Oral Implants Res 2014;25:1041-1050.

13. Eriksson $\mathrm{C}$, Nygren $\mathrm{H}$, Ohlson K. Implantation of hydrophilic and hydrophobic titanium discs in rat tibia: cellular reactions on the surfaces during the first 3 weeks in bone. Biomaterials 2004;25:47594766.

14. Rupp F, Scheideler L, Eichler M, Geis-Gerstorfer J. Wetting behavior of dental implants. Int J Oral Maxillofac Implants 2011;26:1256-1266.

15. Yeo IS. Reality of dental implant surface modification: a short literature review. Open Biomed Eng J 2014;8:114-119.

16. Lang NP, Salvi GE, Huynh-Ba G, Ivanovski S, Donos N, Bosshardt DD. Early osseointegration to hydrophilic and hydrophobic implant surfaces in humans. Clin Oral Implants Res 2011;22:349-356.

17. Sartoretto SC, Alves ATNN, Resende RFB, Calasans-Maia J, Granjeiro JM, Calasans-Maia MD. Early osseointegration driven by the surface chemistry and wettability of dental implants. J Appl Oral Sci 2015;23:279-287.

18. Schliephake $H$, Sewing $A$, Aref A. Resonance frequency measurements of implant stability in the dog mandible: experimental comparison with histomorphometric data. Int J Oral Maxillofac Surg 2006;35:941-946.

19. Blanco J, Alvarez E, Muñoz F, Liñares A, Cantalapiedra A. Influence on early osseointegration of dental implants installed with two different drilling protocols: a histomorphometric study in rabbit. Clin Oral Implants Res 2011;22:92-99.

20. Beutel BG, Danna NR, Granato R, Bonfante EA, Marin C, Tovar N, et al. Implant design and its effects on osseointegration over time within cortical and trabecular bone. J Biomed Mater Res B Appl Biomater 2015. [Epub ahead of print. DOI: 10.1002/jbm.b.33463].

21. Steinemann SG. Titanium--the material of choice? Periodontol 2000 1998;17:7-21.

22. Baires-Campos FE, Jimbo R, Bonfante EA, Fonseca-Oliveira MT, Moura C, Zanetta-Barbosa $D$, et al.. Drilling dimension effects in early stages of osseointegration and implant stability in a canine model. Med Oral Patol Oral Cir Bucal 2015;20:471-479.

23. Meredith N. Assessment of implant stability as a prognostic determinant. Int J Prosthodont 1998;11:491-501.

24. Rozé J, Babu S, Saffarzadeh A, Gayet-Delacroix M, Hoornaert A, Layrolle P. Correlating implant stability to bone structure. Clin Oral Implants Res 2009;20:1140-1145.

25. Ito $Y$, Sato $D$, Yoneda $S$, Ito $D$, Kondo $H$, Kasugai S. Relevance of resonance frequency analysis to evaluate dental implant stability: simulation and histomorphometrical animal experiments. Clin Oral Implants Res 2008;19:9-14.
Received April 17, 2015 Accepted July 27, 2015 